\title{
Loss of Aire-dependent thymic expression of a peripheral tissue antigen renders it a target of autoimmunity
}

\author{
Irina Gavanescu*, Benedikt Kessler ${ }^{\dagger \ddagger}$, Hidde Ploegh ${ }^{\dagger \S}$, Christophe Benoist* ${ }^{* 1 \|}$, and Diane Mathis*१\|| \\ *Section on Immunology and Immunogenetics, Joslin Diabetes Center, "Department of Medicine, Brigham and Women's Hospital, and †'Department of \\ Pathology, Harvard Medical School, Boston, MA 02215
}

Contributed by Diane Mathis, January 22, 2007 (sent for review December 21, 2006)

\begin{abstract}
Both humans and mice with a mutation in the autoimmune regulator (aire) gene develop multiorgan autoimmune disease. Aire was shown to exert its critical function in medullary epithelial cells of the thymus by promoting ectopic expression of peripheral tissue antigens. It was hypothesized that the widespread autoimmunity of Aire-deficient individuals reflects a lack of tolerance induction to the repertoire of peripheral tissue antigens expressed in the thymus of normal individuals. Here, we substantiate this hypothesis by identifying Mucin 6 as a stomach-specific antigen targeted by autoantibodies in gastritisprone mice lacking thymic expression of aire and demonstrate that transcription of the Mucin 6 gene in thymic medullary epithelial cells is indeed Aire-dependent.
\end{abstract}

central tolerance | self-antigen | inflammation

$\mathbf{T}$ olerance to self depends on potentially autoreactive lymphocytes encountering their autoantigen during differentiation in the thymus or after release into the periphery (1-4). T lymphocytes specific for ubiquitous or bloodborne self-antigens are purged in the thymus (5). Nevertheless, T cells that recognize peripheral-tissue antigens (PTAs) were long-thought to be tolerized in the periphery (4). This dichotomous paradigm channeled immunologists' thinking for years, being challenged only recently, when the thymus was found to be capable of ectopically expressing PTAs (6-8). In essence, PTAs project a veritable self-shadow in the thymus, primarily in medullary epithelial cells (MECs) of the stroma (9).

In a subset of MECs, the ectopic expression of a subset of PTAs is promoted by the aire gene (10). In the absence of Aire, autoimmunity develops spontaneously, whereas presentation of the relevant subset of PTAs to emerging thymocytes is abolished. How Aire controls the ectopic expression of PTAs is still in question. Structural features and some of its functional activities indicate that Aire may operate as a transcription factor, in the broad sense of the word, i.e., a molecule that somehow regulates transcript levels $(11,12)$. Aire may also function as an E3 ubiquitin ligase (13), an activity that can influence transcriptional regulators, although this role has been challenged (14).

In both humans and mice, a defect in Aire results in chronic inflammation of internal organs and production of autoantibodies to the tissues of these organs $(10,15)$. Humans with mutations of the AIRE gene develop autoimmune polyendocrinopathycandidiasis-ectodermal dystrophy (APECED), a disease that manifests as an autoimmune attack against adrenal and parathyroid glands, stomach, liver, etc. (15). In mice lacking Aire, chronic inflammation affects similar organs (10), the precise profile of target tissues being subject to genetic influence (16). Like the APECED patient, the murine disease model develops autoantibodies to a panoply of organ-specific antigens.

The primary site of aire gene action is the MEC. Aire deficiency in the nonhematopoietic compartment of the thymic stroma is necessary and sufficient for the development of autoimmunity. MECs have been increasingly implicated in the negative selection of self-reactive thymocytes $(17,18)$, and negative selection is impaired in the absence of Aire $(19,20)$. If Aire-deficient MECs were to fail to tolerize thymocytes to PTAs, the consequent activation of cognate $\mathrm{B}$ and $\mathrm{T}$ lymphocytes once they emerge into the periphery could account for the production of class-switched self-reactive antibodies and multiorgan inflammatory infiltrates. Therefore, we hypothesized that central tolerance to Aire-regulated PTAs is critical in preventing autoimmunity to tissues expressing these antigens in the periphery. A key experiment would be to identify PTAs targeted by autoantibodies in Aire-deficient mice and show that their expression in thymic MECs is Aire-regulated. The issue is a topical one because of recent reports identifying PTAs targeted in aire knockout (KO) animals that are expressed in the thymus, but in an Aire-independent fashion $(21,22)$.

Here, we identify a stomach antigen targeted by autoantibodies in Aire-deficient mice and show that its expression in the thymus depends on Aire. This finding substantiates the notion that central tolerance holds in check organ-specific autoimmunity.

\section{Results}

The severity of chronic inflammation and the spectrum of autoantibody targets vary in different Aire-deficient mouse strains, reflecting both MHC and non-MHC elements of the genetic background (16). In C57BL/6 (B6) ×129 mice, the stomach mucosa is a frequent target of inflammation, and the highest titer autoantibodies develop against the stomach, which, according to immunohistochemistry, recognize mucosal structures (Fig. $1 A$ and $B$ ) (10). Irradiated aire-deficient mice reconstituted with bone marrow precursors from wild-type (WT) donors developed 10- to 100-fold higher autoantibody titers than did straight Aire-KO mice (10). We do not know the mechanism of this enhanced autoimmunity but exploited it experimentally; the studies presented below used serum autoantibodies from aire $\mathrm{KO} / \mathrm{WT}$ radiation bone marrow chimeras to identify a stomach autoantigen target.

Whole-stomach homogenate was incubated with matrixbound Ig from either a WT control mouse or from an Airedeficient mouse reconstituted with WT bone marrow. Bound antigen was eluted and electrophoresed. Silver staining revealed

Author contributions: I.G., H.P., C.B., and D.M. designed research; I.G. and B.K. performed research; I.G., C.B., and D.M. analyzed data; and I.G., C.B., and D.M. wrote the paper.

The authors declare no conflict of interest.

Abbreviations: PTA, peripheral-tissue antigen; MEC, medullary epithelial cell; aire, autoimmune regulator; APECED, autoimmune polyendocrinopathy-candidiasis-ectodermal dystrophy; KO, knockout.

Data deposition: The sequence reported in this paper is available in the GenBank database (accession no. NP859418).

‡Present address: Henry Wellcome Building for Molecular Physiology, Nuffield Department of Clinical Medicine, Oxford University, Oxford OX3 7BN, England.

§Present address: Whitehead Institute of Biomedical Research, Cambridge, MA 02142.

\|To whom correspondence may be addressed. E-mail: cbdm@joslin.harvard.edu or dm@joslin.harvard.edu.

(C) 2007 by The National Academy of Sciences of the USA 
A

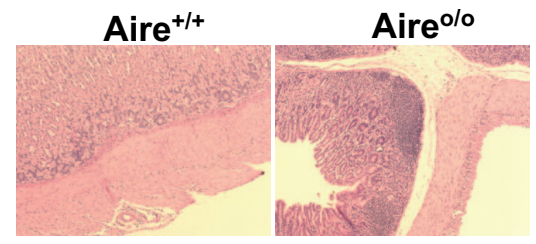

B
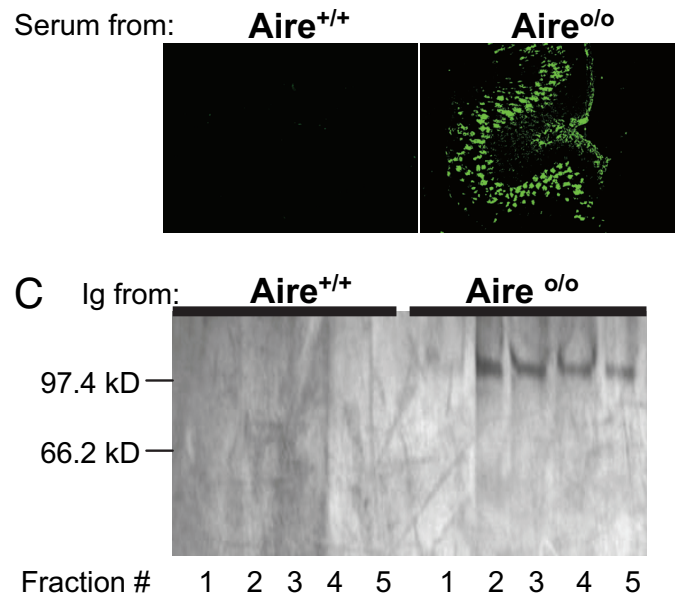

Fig. 1. Stomach autoimmunity in Aire-deficient mice. Chronic inflammation of the stomach in aire KO mice. (A) H\&E-stained paraffin stomach sections with normal gastric anatomy from a 20-week-old WT mouse (Left, magnification $\times 10$ ); inflammatory infiltrates in the stomach mucosa of an age- and sexmatched aire KO mouse (Right). (B) Indirect immunofluorescence staining of frozen sections from a Rag-deficient mouse's stomach with serum from aire KO $($ Right, $\times 10)$ or WT $($ Left, $\times 10)$ mice. Positive staining is indicated by green fluorescence. (C) A stomach antigen of $100 \mathrm{kDa}$ immunoprecipitated by autoantibodies from aire KO/WT chimeras and visualized by silver staining on an SDS-PAGE gel. Immunoprecipitating antibodies were derived from sera of 20-week-old WT (antigen fraction numbers 1-5) (Right) or chimeric Airedeficient recipients of WT bone marrow (antigen fractions 1-5) (Left).

a single band of $\approx 100 \mathrm{kDa}$ for the sera from aire $\mathrm{KO} / \mathrm{WT}$ chimeras, missing with the sera from WT animals (Fig. $1 C$ ). To identify the $100-\mathrm{kDa}$ antigen precipitated by sera from the chimeric mice, we eluted the protein from the gel, digested it using trypsin, and analyzed it by tandem mass spectrometry (MS). The MS analysis was performed multiple times by using immunoprecipitated antigen trypsinized either in the polyacrylamide gel or in solution. The analyses yielded a set of peptide mass spectra used in turn to predict the peptide sequences (Fig. $2 A$ and $B$ ). The predicted peptide sequences were subjected to searches of the National Center for Biotechnology Information nonredundant database and identified the antigen to be a gastric, secreted, gel-forming mucin or Mucin 6 (Fig. 2C), with MASCOT (Matrixscience, London, U.K.) probability scores of 391 (gel sample) and 160 (solubilized sample). No other candidate protein had a score beyond 52 .

The murine mucin 6 gene has 33 in silico-predicted exons spread over a $28.8-\mathrm{kb}$ genomic region (23). If this prediction is correct, the muc6 coding region should be 8,700 base pairs long and encode a protein with a molecular mass of $\approx 300 \mathrm{kDa}$; the protein's predicted functional domains are diagrammed in Fig. $2 D$. The $100-\mathrm{kDa}$ antigen immunoprecipitated by aire $\mathrm{KO} / \mathrm{WT}$ chimera sera may be a splice variant or proteolytic cleavage product, either physiologic or experimental, of Mucin 6. Given the size discrepancy between the predicted and the immunoprecipitated protein, we sought to verify the MS identification of the autoantibody target by preparing recombinant Mucin 6 as a GST fusion protein and assaying serum reactivity to it. Whereas sera from WT mice of mixed B $6 \times 129$ genetic background did not contain anti-Mucin antibodies when used to probe Western blots of recombinant Mucin 6 (Fig. $3 A$ Left), sera from their Aire-deficient littermates did (Fig. $3 A$ Right). Second, we explored strain-to-strain variation of the anti-Mucin autoantibody response by testing sera from aire $\mathrm{KO}$ and $\mathrm{WT}$ mice on the BALB/c, NOD, and B6 backgrounds. Aire-deficient mice of strains prone to gastritis (BALB/c, NOD; see ref. 16) also generated autoantibodies to recombinant Mucin 6 (Fig. 3B). In contrast, Aire-deficient B6 mice, which rarely develop gastritis, infrequently harbored such antibodies. WT littermates of either strain did not develop anti-Mucin antibodies.

Last, we asked whether the generation of an anti-Mucin 6 autoantibody response in mice devoid of Aire in the thymus was accompanied by a loss of thymic mucin 6 expression. Mucin 6 was transcribed in the thymus of WT mice, albeit at a level 700 -fold lower than that in the stomach; there were only trace levels of Mucin 6 transcripts in a negative-control organ, the kidney (Fig. $4 A$ ). At the whole-thymus level, WT mice expressed 54-fold more mucin 6 than did aire KO mice (Fig. 4B). Expression of mucin 6 transcripts was also clearly Aire-dependent at the level of purified MECs (Fig. 4C).

\section{Discussion}

The experiments presented herein addressed the hypothesis that Aire promotes immunologic tolerance by driving ectopic expression of peripheral tissue antigens in medullary epithelial cells of the thymus. That Aire controls tolerance was inferred from the multiorgan autoimmunity characteristic of aire mutant humans and mice $(10,21,24,25)$, and that it does so by up-regulating thymic transcription of thousands of genes encoding PTAs was indicated by comparing the gene expression profiles of MECs from aire KO and aire WT mice (10). Although this latter finding is highly suggestive, it is necessary to "close the circle" by identifying antigen targets of the autoreactive response in mice lacking Aire and demonstrating that their expression in the thymus is indeed Aire-dependent.

This became imperative because of several cases of a disjunction between Aire control of autoimmunity to a particular antigen and Aire regulation of its expression in MECs. For example, autoantibodies against fodrin and pancreas-specific protein disulfide isomerase were found in association with autoimmunity directed at the salivary gland or exocrine pancreas, respectively, in aire $\mathrm{KO}$ mice; yet, in neither case was the corresponding gene's transcription reduced in the thymus $(21$, 22). In addition, it was reported that Aire strongly controlled clonal deletion of thymocytes recognizing membrane-anchored ovalbumin expressed under the dictates of the insulin promoter, although it did not regulate MEC expression of this neoselfantigen (19). It remains possible that in these cases there was a qualitative difference in the proteins expressed in aire $\mathrm{KO}$ versus aire WT MECs, e.g., an alternative splice form, such that tolerance to some of the antigen's epitopes was not imposed in the KO animals. This scenario is similar to that invoked to explain autoreactivity to proteolipid protein and susceptibility to experimental autoimmune encephalomyelitis in selected mouse strains (26). Another possibility is that the half-life of expressed peripheral tissue proteins differed in the mutant and WT MECs, perhaps a manifestation of Aire's proposed E3 ubiquitin ligase activity (13), akin to what has been suggested for the $\alpha$-subunit of the gastric $\mathrm{H} / \mathrm{K}$ ATPase (27). Collectively, these findings have served to raise the possibility that Aire performs functions in addition to regulating MEC transcription of PTA genes.

This study focused on the strong autoimmune responses against the stomach mucosa of aire KO/WT bone marrow chimeras (also seen in straight Aire-deficient mice of several genetic backgrounds). Antistomach autoimmunity was manifest by both inflammation of the mucosa and the generation of 
A

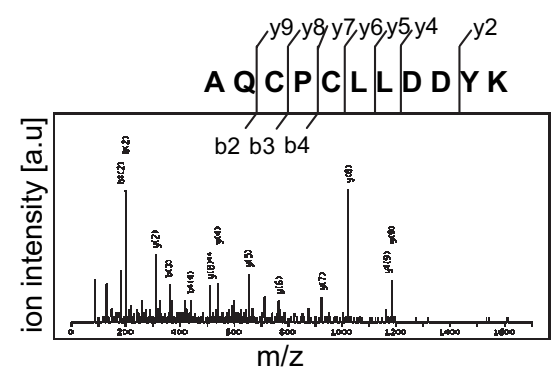

\begin{tabular}{|l|l|l|l|l|l|}
\hline Mr(expt) & Mr(calc) & Delta & Score & Expect & Peptide \\
\hline 999.53 & 999.57 & -0.03 & 27 & 22 & GILLWGWR \\
\hline 1239.51 & 1239.54 & -0.03 & 32 & 6.5 & LCGLCGNFDGK \\
\hline 1265.54 & 1265.58 & -0.04 & 72 & 0.00076 & IDNEFLSEDGK \\
\hline 1348.5 & 1348.54 & -0.03 & 54 & 0.044 & TFSYDSQACDR \\
\hline 1381.57 & 1381.6 & -0.03 & 30 & 12 & AQCPCLLDDYK \\
\hline 1472.81 & 1472.83 & -0.02 & 43 & 0.62 & IIMELGASVVTVNK \\
\hline 1746.81 & 1745.87 & -0.03 & 21 & 81 & IVISEDEVITNNGDTK \\
\hline 1971.92 & 1971.96 & -0.04 & 55 & 0.029 & SGYSHSETSLVAIMYLS \\
\hline 2275.1 & 2275.13 & -0.04 & 26 & 22 & YAQICNQLLTLVSPGCDVPK \\
\hline
\end{tabular}

C

MLRVRQLLLLLLFRGPLIDAGAWTGDVTDSDTEDNLQSSPEKGWCSTWGAGHFSTFDGHEYNFQGMCNYIFTATCGDDVPATFSIQLRRDMEGNISRIIMELGASVVTVNKETISVRDIGVVSLPYT SNGLQITPYGQSVQLVAKQLELELVITWGPDAHLTEGQGGDEVGTPGTLKQESKGSPAWAGSSLCIPTETNSTTPQVQVETKYMGK LCGLCGNFDGKIDNEFLSEDGKLLEAHKYATLQKLDDP NEICAHEAIPSTIILKTRYAQICNQLLTLVSPGCDVPKETLMLSCADMAACARPGQPNCSCATLSEYSRRCSMTGQPVRNWRTPALCPMSQCPANQVYQECGEVIIKTCSNPQHSCSSPCT
FGCFCPHGTLDISGNOSCVPVNOCPCMLNGMVYGPGITKTACQTCQCTMGRWTCTKOPCPGHCSLEGGSVTTTFDARPYRFHGTCTYTLOSPOLPNEGTLAVYDK SGYSHSETSLVAIM FGCFCPHGTLLDDISGNQSCVPVNQCPCMLNGMVYGPGEITKTACQTCQCTMGRWTCTKQPCPGHCSLEGGSFVTTFDARPYRFHGTCTYTLLQSPQLPNEGTLMAVYDK SGYSHSETSLVAIM YLSKKDKIVISEDEVITNNGDTKLLPYKTHNITIFRQTSTHLQMATTFGLELVFQMQPVFQVYITVGPQFKGQTRGLCGNFNGDTDDFTTSMGIDEGTASLFVDSWRAGNCPAALER EMDPCSM NCPEGTYLNHKAECVHKAQCPCLLDDYKFVQADQSTMINGVICHCINGRLSCPRQAEMFFASCPEPKTFQSCSQSSEDKFGAACAPTCQMLATGIDCVPTKCESGCVCPKGLYENSDGQC VPAEECPCPAGVSYPGGFELHTDCKTCTCSQGRWTCQLSTQCPSTCVLYGEGHIITFDGRFVFDGDCEYMLATDDCGANSSQPTFKVLTENVICGKSGVTCSRAIKISLGGLFITMADSNYTVSGEE PLVHLKVKPSPLNLVLDIDIPGRLNLTLVWNKHMSVSIKIRRATQDALCGLCGNANGNMKDDFETRSKYVASNELEFVNSWKESPLCGDASYAVDPCSLNTFRRSWAERKCNIINSQTFAACHSKVY HL PYYEACVRDACGCDTGGDCECLCDAVAAYAKACLDKGVCVDWRTPDFCPIYCDFYNTHTLVGENEYQYAQESNCTWHYQPCLCPGSLGSFPDTNTEGCYNCSQNEYFDHSEGTCVPCAPPTTTLP STSQEGTPTSKIPVTQTTTHRVPSRCITNQSTTMFQTTTVQEAEITQTLAPSTYTTNDITKTQNLFSTAPHLSETSAVTAHQSTPTAVSANSIKPTMSSTGTPVVHTTSGTSSSPQTPRTTHPSTTVAVSGT VHTTGLPSGTSVHTTTNFPTHSGPQSSLSTHLPLFSTLSVTPTTEGLNTQSTPIPAITNSLMTTGGLTGTPPVHTTSGTTSSPQTPRTTHPFSTVAVSNTKHTTGVSLETSVQTTIASPTPSAPQTSLATHL PFSSTSSVTPTSEVIITPTPQHILSSASTSTITGNILPTTIGKTGSPHTSVPVIYTTSAITQTKTSFSTDRTSTSTSAPHLSETSAVTAHQSTPTAVSANSIKPTMSSTGTPVVHTTSGTTSSPQTPRTTHPST TVAVSGTVHTTGLPSGTSVHTTINFPTHSGPOSSLSTHLPLFSTLSVTPTTEGLNTPTSPHSLSVASTSMPLMTVLPTLEGTRPPHTSVPVTYTTTAATQTKSSFSTDRTSAPHLSOPSTVTPTOSTPIP SATOTKTS SAITQTKTSFSTDRTSTSTSAPHLSETSAVTAHQSTPTAVANSIKPTMSSTGTPVHTTTSGTTSSPQTPRTTHPSTTVAVSGTVHTTGLPSGTSVHTTTNFPTHSGPQSSLSTHLPLFSTLSVTPT TEGL
NTPTSPHSLSAASTSMPLMTVLPTTLETRPPHTSVVTYTTTAATQTKSSFSTDRTSTPHLSQSSTVTPTQPTPIPATTNSPMTTVGLTGTPVHTPSGTSSIATTPHTTHSLPTAASSTTLSTA PQFRT SEQSTTTFPTPSAPQTSLVTSLPPFSTSSVSPTDEIHITSTNPHTVSSVSMSRPVSTILQTTIEVTTPPNTSTPVTHSTSATTEAQGSFSTERTSTSYLSHPSSTTVHQSTAGPVITSIKSTMGVTGTPPVHT TSGTTSSPQTPHSTHPISTAAISRTTGISGTPFRTPMKTTITFPTPSSLQTSMATLFPPFSTSVMSSTEIFNTPTNPHSVSSASTSRPLSTSLPTTIKGTGTPQTPVSDINTTSATTQAHSSFPTTRTSTSHLS LPSSMTSTLTPASRSASTLOYTPTPSSVSHSPLLTTPTASPPSSAPTFVSPTAASTVISSALPTIHMTPTPSSRPTSSTGLLSTSKTTSHVPTFSSFSSKSTTAHLTSLTTQAATSGLLSSTMGMTNLPSSG TLTLQVFSSCVCSPLQCKN

D
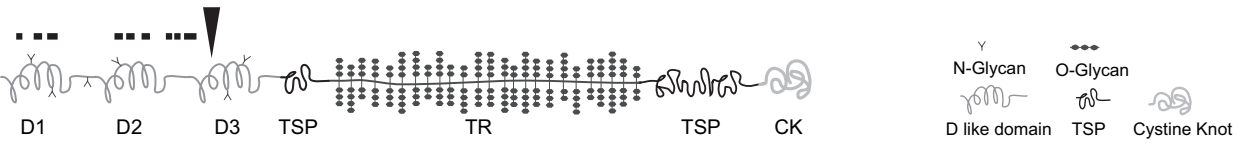

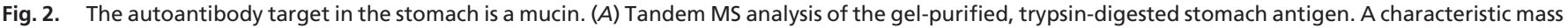

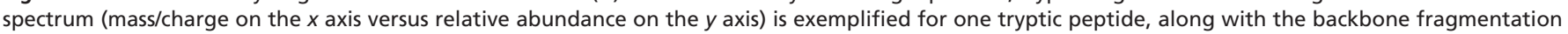

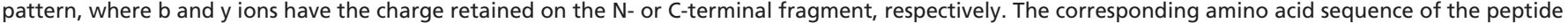

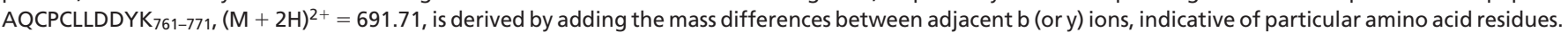

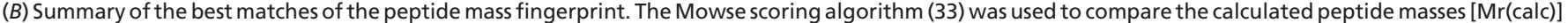

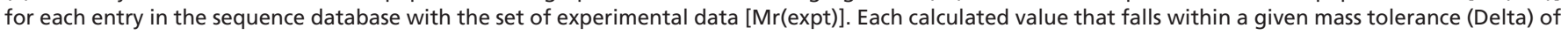

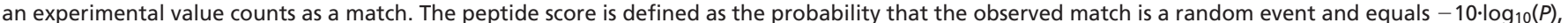

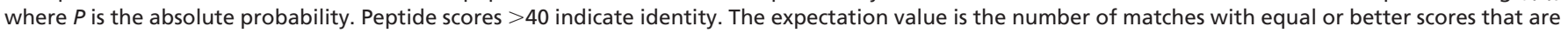

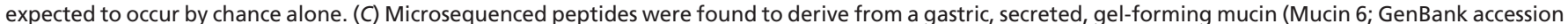

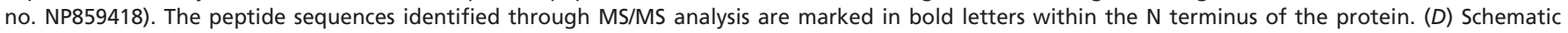

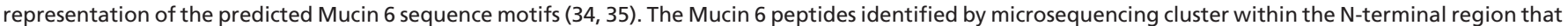

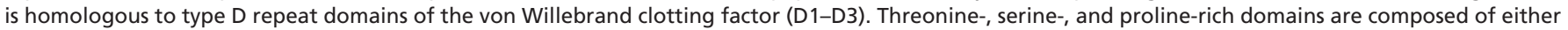

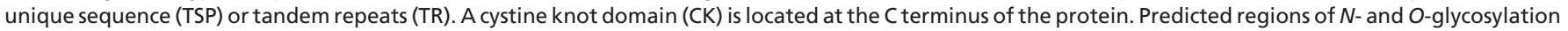
are marked symbolically within protein sequence motifs.

antimucosal antibodies. The target of the latter was quite restricted: mucin 6. It is worth noting that transcripts encoding mucin 6 were expressed in the MECs of aire WT mice and were strikingly reduced in their aire KO littermates. The conclusion must be that the absence of mucin 6 in thymic MECs permitted the export of $\mathrm{T}$ lymphocytes capable of recognizing it, $\mathrm{T}$ cells, which eventually invaded peripheral tissues expressing it and helped cognate B cells make an antibody response against it. While this manuscript was in preparation, an analogous conclu-

A
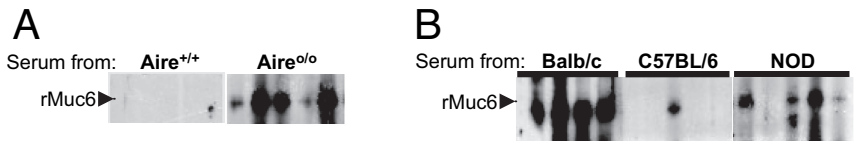

Fig. 3. Generation of anti-Mucin 6 autoantibodies versus gastric inflammation. (A) Immunoblots of recombinant Mucin 6 with sera from WT (Left) and aire KO littermate mice (Right) on a mixed B6 $\times 129$ background. The latter, but not the former, develop gastritis. (B) Immunoblots of recombinant Mucin 6 with sera from gastritis-susceptible, Aire-deficient mice on the BALB/c (Left) and NOD (Right) backgrounds, and sera from gastritis-resistant B6 Airedeficient mice (Center). sion concerning Aire control of tolerance to eye antigens was reported by Anderson and colleagues (28).

Although clear, our results raise a certain number of questions. What underlies the restricted set of target antigens in aire-deficient mice? Breakdown of the Aire-dependent transcription of PTA genes should yield broad autoreactivity, corresponding to the large number and diversity of thymic PTA transcripts regulated by Aire. However, only certain organs are attacked in Aire-deficient mice or humans; within these organs, very specific structures are targeted, as evidenced by immunohistology, and within these structures, only a limited number of proteins are targeted, according to Western blotting $(10,16)$. Although a number of processes could serve to limit the antigens targeted, e.g., cross-tolerance with another protein or inaccessibility within the organ, a major factor must be the classical phenomenon of MHC restriction. Quite simply, in a number of cases, potentially antigenic proteins do not yield peptides that can bind sufficiently well to the particular MHC molecules expressed by an individual to be able to elicit an immune response. B cell tolerance to a number of antigens may be another element limiting the range of autoantibody targets when a central mechanism of $\mathrm{T}$ cell tolerance breaks down. 

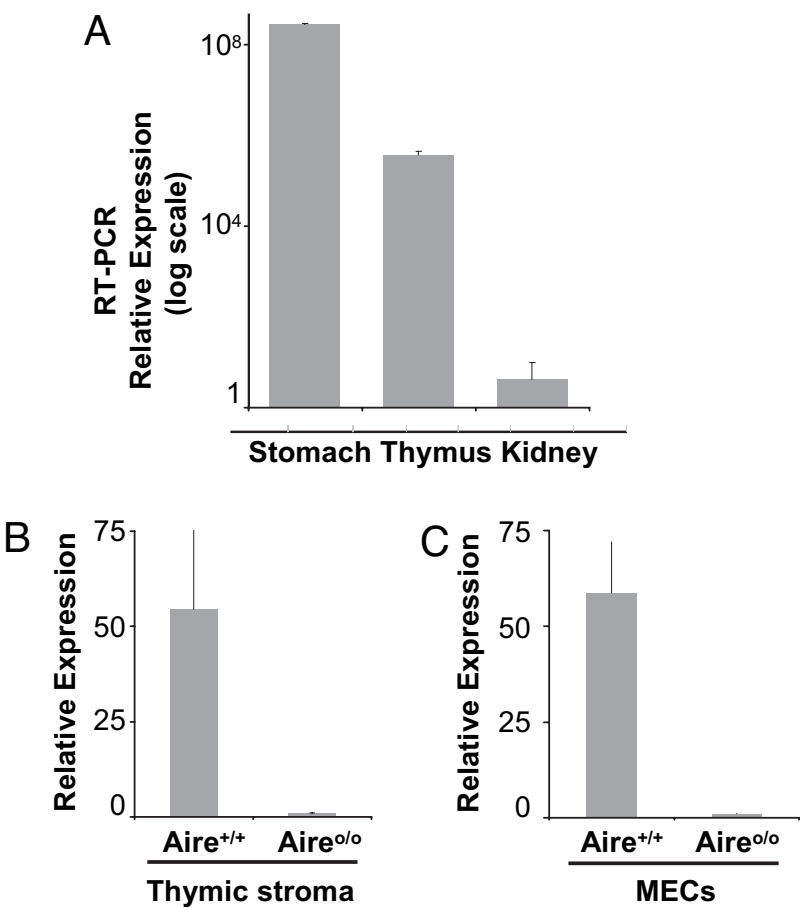

Fig. 4. Aire regulates thymic mucin 6 expression. (A) Mucin 6 expression levels were quantitated by RT-PCR on CDNA prepared from diverse tissues of a 6-week-old mouse. The ratios of muc6 to hprt expression for each tissue are plotted on a logarithmic scale in arbitrary units. (B) RT-PCR assay of mucin 6 expression in thymic epithelia prepared by teasing out the thymocytes from individual thymi of 4-week-old aire KO and WT mice. (C) RT-PCR assay of mucin 6 transcription levels in sorted thymic MECs from WT and aire KO mice. In all cases, results are representative of three independent experiments.

Last, a word on the difference in autoantibody targets recently documented in mice versus humans (29): significantly different Aire functions in the two species is no doubt too simplistic an answer. One needs to keep in mind that the MHC molecules in mice and humans are distinct and thus should not be surprised when different immune responses are made; this would be entirely expected according to the dictates of MHC restriction. This explanation has already been substantiated for the markedly different autoimmune manifestations in different mouse strains (16).

\section{Materials and Methods}

Mice and Sera. Aire KO mice (10) and WT littermates on the NOD, B6, BALB/c, or mixed B6 $\times 129$ background were bred from heterozygous parents and maintained at the Harvard Medical School barrier animal facility, according to Institutional Animal Care and Usage Committee approval no. 02954. Sera were obtained from tail bleeds.

Bone Marrow Chimeras. Aire KO/WT chimeras were prepared as described (10). In brief, bone marrow was harvested from femurs and tibiae of 6-week-old WT donors. Bone marrow cells $\left(10^{7}\right)$ were injected into the tail veins of 6 -week-old WT or aire KO recipients, which had been lethally irradiated (1,000 rad). Aire $\mathrm{KO} / \mathrm{WT}$ chimeras were used as a source of serum antibodies 8 weeks after reconstitution.

Immunoprecipitation. Serum antibodies were titrated upon serial endpoint dilution by immunohistochemical staining of frozen stomach substrates, as already described (10). Immunoprecipitation was performed by binding $250 \mu \mathrm{g}$ of serum Ig from Aire-deficient mice to protein G-Sepharose (Amersham Bio- sciences, Piscataway, NJ). Ig was cross-linked at room temperature to protein G-Sepharose beads with $13 \mathrm{mg} / \mathrm{ml}$ dimethyl pimelimidate (Sigma-Aldrich, St. Louis, MO) dissolved in $0.2 \mathrm{M}$ triethanolamine and PBS ( $\mathrm{pH} 8)$. The reaction was quenched with a 10-fold higher volume of $50 \mathrm{mM}$ ethanolamine in PBS. Noncross-linked $\mathrm{Ab}$ was removed with $0.1 \mathrm{M}$ glycine ( $\mathrm{pH} 2.5$ ). To prepare tissue lysates, we homogenized organs of (recombinase-activating gene) $R a g \mathrm{KO}$ mice in buffer containing $50 \mathrm{mM}$ Tris ( $\mathrm{pH} 8), 150 \mathrm{mM} \mathrm{NaCl}, 1 \%$ Nonidet P-40, and a mixture of protease inhibitors (Roche Diagnostics, Indianapolis, IN), at 20 $\mu \mathrm{l} / \mathrm{mg}$ wet tissue. Organ homogenates were clarified by highspeed centrifugation, and supernatants were incubated with bead-bound Ig. Beads were washed, and bound antigen was eluted with $0.1 \mathrm{M}$ glycine ( $\mathrm{pH}$ 2.5). Eluted protein was subjected to electrophoresis and visualized by silver staining. Silver staining was performed with a commercially available set of reagents (Invitrogen, Carlsbad, CA), compatible with subsequent MS, according to the manufacturer's recommendation.

Tryptic Digestion and Analysis by Electrospray Tandem Mass Spectrometry (MS/MS). In-gel and in-solution tryptic digestion was performed essentially as described (30). The samples were subjected to a nanoflow liquid chromatography (LC) system (Waters, Milford, MA) equipped with a Picofrit column $(75-\mu \mathrm{m}$ i.d., $9.8 \mathrm{~cm}$; NewObjective, Woburn, MA) at a flow rate of $\approx 150$ $\mathrm{nl} / \mathrm{min}$ by using a Nanotee (Waters) $16 / 1$ split (initial flow rate $5.5 \mu \mathrm{l} / \mathrm{min}$ ). The LC system was directly coupled to a quadrupole time-of-flight micro tandem mass spectrometer (Micromass, Manchester, U.K.). Analysis was performed in survey-scan mode, and parent ions with intensities $>7$ were sequenced in MS/MS mode by using MassLynx 4.0 Software (Micromass). MS/MS data were processed and subjected to database searches by using MASCOT (Matrixscience) against the National Center for Biotechnology Information nonredundant database. In all searches, oxidation of methionine and carbamidomethylation of cysteine residues were considered as modifications. Matches for proteins were accepted as significant if scores were $>75$, based on the MASCOT Probability Mowse Score. At least four peptides were found for each identified protein species.

Thymic Epithelial Cells. Thymic epithelial cells were prepared as in refs. 10 and 31. In brief, pools of five thymi of 3- to 5-week-old mice were digested at $37^{\circ} \mathrm{C}$ with collagenase, dispase (each at $0.2 \mathrm{mg} / \mathrm{ml}$ ), and $25 \mu \mathrm{g} / \mathrm{ml}$ DNase in RPMI medium 1640 and $2 \%$ FCS. A homogeneous cell suspension was obtained after $30 \mathrm{~min}$ of enzymatic digestion, and EDTA was added to a final concentration of $10 \mathrm{mM}$ for an additional $5 \mathrm{~min}$. Cells were separated on a discontinuous Percoll gradient. The MEC-enriched fraction was harvested and stained with G8.8 fluorescein (FITC), anti-CD45 PECy5 (eBioscience, San Diego, CA), and anti Ly-51 phycoerythrin (BD PharMingen, San Diego, CA). MECs were sorted according to the phenotype $\mathrm{CD} 45^{-}, \mathrm{G} 8.8^{+}$, Ly51 ${ }^{\text {int }}$.

RNA Isolation and Reverse Transcription. Total RNA was isolated from organs or sorted MECs as described (31, 32). TRIzol reagent was used for RNA isolation according to the manufacturer's protocol (Invitrogen). RNA was treated with DNase and subjected to reverse transcription with random hexamers or oligo(dT) primers.

Real-Time (RT) PCR Assay. The expression levels of mucin 6 were assayed with gene-specific Taqman primers and probes designed to span exon-exon junctions and were normalized to tissue cDNA content on hypoxanthine guanine phospho-ribosyltransferase (hprt). Muc6 primers: forward, 5'-TGC TCC CAG AAT GAG TAC TTC GA-3'; reverse, 5'-CAG AGG TGG AAC TGT GAA ACT CAG T-3'; probe, FAM-AGG GAC CTG TGT ACC CTG TGC TGC ACC A-TAMRA. HPRT primers: for- 
ward, 5'-GAC CGG TCC CGT CAT GC-3'; reverse, 5'-CAG TCC ATG AGG AAT AAA CAC TTT TTC-3'; probe, VICCCG-CAG TCC CAG CGT CGT GAT T-TAMRA. RT-PCRs were performed in a final volume of $25 \mu \mathrm{l}$, with $900 \mathrm{nM}$ of the forward and reverse primers and $200 \mathrm{nM}$ of the probe, added to $2 \times$ Taqman master mix (Applied Biosystems, Foster City, CA) containing AmpliTaq Gold polymerase. Duplicate reactions were cycled on an Applied Biosytems 7700 Sequence Detection System machine (annealing temperature $60^{\circ} \mathrm{C}, 40$ cycles). The standard-curve method was used for the analysis of mucin 6 or hprt gene expression from organ- or MEC-derived cDNA. Standard curves had comparable slopes for quantitation and normalization assays.

Mucin 6 Cloning and Recombinant Protein Preparation. The sequence encoding the N-terminal $100 \mathrm{kDa}$ of Mucin 6 was amplified by PCR from stomach cDNA and was cloned in a pGEx-4T plasmid vector as a GST fusion protein; sequencing confirmed that mucin 6 and the tag were cloned in frame, the construct was transformed in the protease-deficient BL21 Escherichia coli strain, and protein synthesis was induced with $1 \mathrm{mM}$ isopropyl $\beta$-D-thiogalactoside upon shaking at $37^{\circ} \mathrm{C}$ for $3 \mathrm{~h}$. Bacteria were lysed by sonication, and inclusion bodies were solubilized in $8 \mathrm{M}$ urea.

1. Alferink J, Aigner S, Reibke R, Hammerling GJ, Arnold B (1999) Immunol Rev 169:255-261.

2. Starr TK, Jameson SC, Hogquist KA (2003) Ann Rev Immunol 21:139-176.

3. Palmer E (2003) Nat Rev Immunol 3:383-391.

4. Walker LS, Abbas AK (2002) Nat Rev Immunol 2:11-19.

5. Ohashi PS (2003) Curr Opin Immunol 15:668-676.

6. Heath VL, Moore NC, Parnell SM, Mason D (1998) J Autoimmun 11:309-318

7. Kojima K, Reindl M, Lassmann H, Wekerle H, Linington C (1997) Int Immunol 9:897-904.

8. Sospedra M, Ferrer-Francesch X, Dominguez O, Juan M, Foz-Sala M, Pujol-Borrell R (1998) J Immunol 161:5918-5929.

9. Kyewski B, Derbinski J, Gotter J, Klein L (2002) Trends Immunol 23:364-371.

10. Anderson MS, Venanzi ES, Klein L, Chen Z, Berzins SP, Turley SJ, von Boehmer H, Bronson R, Dierich A, Benoist C, et al. (2002) Science 298:13951401.

11. Bjorses P, Halonen M, Palvimo JJ, Kolmer M, Aaltonen J, Ellonen P, Perheentupa J, Ulmanen I, Peltonen L (2000) Am J Hum Genet 66:378-392.

12. Pitkanen J, Doucas V, Sternsdorf T, Nakajima T, Aratani S, Jensen K, Will H, Vahamurto P, Ollila J, Vihinen M, et al. (2000) J Biol Chem 275:16802-16809.

13. Uchida D, Hatakeyama S, Matsushima A, Han H, Ishido S, Hotta H, Kudoh J, Shimizu N, Doucas V, Nakayama KI, et al. (2004) J Exp Med 199:167-172.

14. Bottomley MJ, Stier G, Pennacchini D, Legube G, Simon B, Akhtar A, Sattler M, Musco G (2005) J Biol Chem 280:11505-11512.

15. Betterle C, Dal Pra C, Mantero F, Zanchetta R (2002) Endocr Rev 23:327-364

16. Jiang W, Anderson MS, Bronson R, Mathis D, Benoist C (2005) J Exp Med 202:805-815.

17. Degermann S, Surh CD, Glimcher LH, Sprent J, Lo D (1994) J Immunol 152:3254-3263.

18. Klein L, Roettinger B, Kyewski B (2001) Eur J Immunol 31:2476-2486.
Western Blotting. Twenty micrograms of recombinant protein were mixed with sample buffer $(62.5 \mathrm{mM}$ Tris $\cdot \mathrm{HCl}, \mathrm{pH} 6.8,25 \%$ glycerol, $2 \%$ SDS, $1 \%$ bromophenol blue, and $5 \%$ 2-mercaptoethanol) and heated at $96^{\circ} \mathrm{C}$. The protein was resolved on a $10 \%$ curtain gel by SDS-PAGE and was transferred onto a PVDF membrane (Bio-Rad, Hercules, CA). The membrane was blocked for $1 \mathrm{~h}$ in a $5 \%$ milk solution in Tris-buffered saline (25 $\mathrm{mM}$ Tris, $\mathrm{pH} \mathrm{7.6}$, and $150 \mathrm{mM} \mathrm{NaCl}$ ) and was probed in a Protean II Multiscreen apparatus (Bio-Rad) with sera diluted 1:500 for $2 \mathrm{~h}$ at $4^{\circ} \mathrm{C}$. The membrane was washed with Tris-buffered saline and $0.1 \%$ Tween 20, incubated with HRPconjugated donkey anti-mouse IgG (1:3,000; Jackson ImmunoResearch, West Grove, PA), and revealed with SuperSignal chemiluminescent substrate reagents (Pierce, Rockford, IL) by autoradiography.

We thank Eric Spooner for technical assistance with MS analyses, Adriana Ortiz-Lopez for help with RT-PCR, Girijesh Buruzula for help with cell sorting, and Vanessa Tran for the care of the mouse colony. This work was supported by National Institutes of Health Grants R01 DK60027 (to C.B. and D.M.), T32 CA09382-22 and F32 AI62010-01 (to I.G.), and P30 DK36836 (to the Joslin Diabetes and Endocrinology Research Center Core Facilities).

19. Anderson MS, Venanzi ES, Chen Z, Berzins SP, Benoist C, Mathis D (2005) Immunity 23:227-239.

20. Liston A, Lesage S, Wilson J, Peltonen L, Goodnow CC (2003) Nat Immunol $4: 350-354$.

21. Kuroda N, Mitani T, Takeda N, Ishimaru N, Arakaki R, Hayashi Y, Bando Y, Izumi K, Takahashi T, Nomura T, et al. (2005) J Immunol 174:1862-1870.

22. Niki S, Oshikawa K, Mouri Y, Hirota F, Matsushima A, Yano M, Han H, Bando Y, Izumi K, Matsumoto M, et al. (2006) J Clin Invest 116:1292-1301.

23. Desseyn JL, Laine A (2003) Genomics 81:433-436.

24. Perheentupa J (2006) J Clin Endocrinol Metab 91:2843-2850.

25. Ramsey C, Winqvist O, Puhakka L, Halonen M, Moro A, Kampe O, Eskelin P, Pelto-Huikko M, Peltonen L (2002) Hum Mol Genet 11:397-409.

26. Klein L, Klugmann M, Nave K-A, Tuohy VK, Kyewski B (2000) Nat Med 6:56-61.

27. van Driel IR, Read S, Zwar TD, Gleeson PA (2005) Curr Opin Immunol 17:570-576.

28. Devoss J, Hou Y, Johannes K, Lu W, Liou GI, Rinn J, Chang H, Caspi R, Fong L, Anderson MS (2006) J Exp Med 203:2727-2735.

29. Pontynen N, Miettinen A, Petteri Arstila T, Kampe O, Alimohammadi M, Vaarala O, Peltonen L, Ulmanen I (2006) J Autoimmun 27:96-104.

30. Kocks C, Maehr R, Overkleeft HS, Wang EW, Iyer LK, Lennon-Dumenil AM, Ploegh HL, Kessler BM (2003) Mol Cell Proteomics 2:1188-1197.

31. Derbinski J, Schulte A, Kyewski B, Klein L (2001) Nat Immunol 2:1032-1039.

32. Auffray C, Rougeon F (1980) Eur J Biochem 107:303-314.

33. Pappin DJ, Hojrup P, Bleasby AJ (1993) Curr Biol 3:327-332.

34. Dekker J, Rossen JW, Buller HA, Einerhand AW (2002) Trends Biochem Sci 27:126-131.

35. Escande F, Porchet N, Bernigaud A, Petitprez D, Aubert JP, Buisine MP (2004) Biochim Biophys Acta 1676:240-250. 